\title{
Study ANd EFfect of Process Parameters on External CYLINDRICAL SURFACES OF TITANIUM ALLOYS BY Electro Chemical Honing (ECH) Process
}

\author{
P Sudhakar Rao, Pramod Kumar Jain, Dheerendra Kumar Dwivedi
}

Department of Mechanical \& Industrial Engineering, Indian Institute of Technology Roorkee-247667, India

\begin{abstract}
Electro Chemical Honing is a precision machining process for machining difficult-to-cut materials and to shape free-form surfaces by ECM process with combined Mechanical Honing operation. In ECH, most of the material is removed by electrochemical dissolution process. As work piece hardness is not a limiting factor for ECH process, the work piece is machined without inducing any residual stresses and without any tool wear to achieve a nano level finish and hence, it can be used widely in automobile, avionics, petrochemical and power generation industries. This has made ECH an ideal choice for improving the surface quality of critical components like Inconel, Incolay, Titanium \& Nickel alloys etc. Titanium alloy is used for carrying out the experimentation to describe the material removal \& surface roughness characteristics and also highlights the four key process parameters \& their effect on ECH process. The key feature of the newly developed experimental setup is also discussed.
\end{abstract}

Keywords: Electro Chemical Honing; Titanium alloy; Key Process Parameters; Microstructure Characteristics; Key Findings
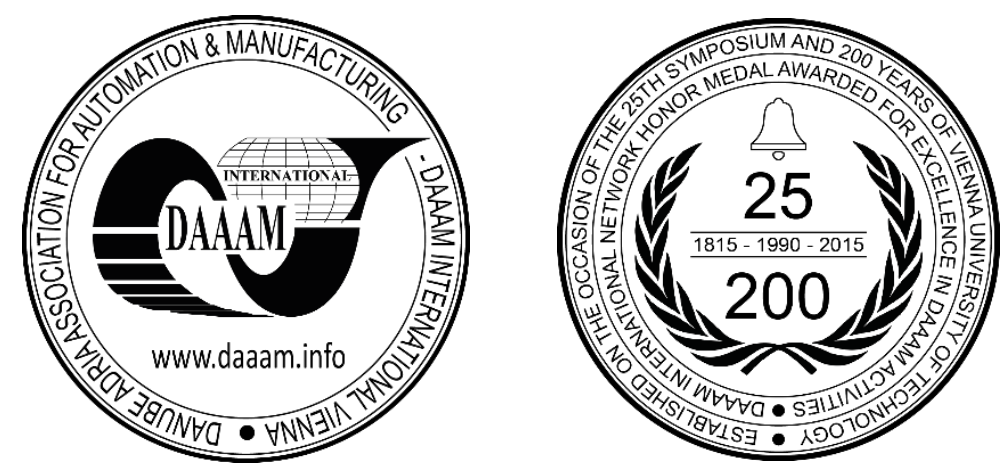

This Publication has to be referred as: Rao, P[.] S[udhakar]; Jain, P[ramod] K[umar] \& Dwivedi, D[heerendra] K[umar] (2016). Study and Effect of Process Parameters on External Cylindrical Surfaces of Titanium Alloys by Electro Chemical Honing (ECH) Process, Proceedings of the 26th DAAAM International Symposium, pp.0570-0579, B. Katalinic (Ed.), Published by DAAAM International, ISBN 978-3-902734-07-5, ISSN 1726-9679, Vienna, Austria DOI: $10.2507 / 26$ th.daaam.proceedings.078 


\section{Introduction}

With the new innovations and recent developments in manufacturing technology, more and more challenging problems are faced by the technocrats and engineers in the field of manufacturing. The drastic development in recent years in most of the advanced industries like aerospace, automobile, nuclear power, missiles and turbine industries has been accompanied by the development of very hard, high strength, difficult-to-machine non-ferrous materials and alloys. Titanium is one of the most potential among them to overcome all difficulties [1]. Titanium alloys are extensively used in aerospace, petroleum and chemical industry due to their specific strength, strong corrosion resistance and ability to retain high strength at elevated temperatures. Recently, the titanium and its alloys are also widely used as biomedical materials to act as a load bearing implant in orthopaedic surgery due to their biocompatibility, excellent corrosion resistance, good mechanical properties and weight of lightness [2].Producing complicated geometries and maintaining high dimensional accuracy in such materials become extremely difficult with the conventional machining methods. However, titanium and its alloys have poor machinability due to their low thermal conductivity, high chemical reactivity and low modulus of elasticity resulting in high cutting temperature, rapid tool wear and high level of vibration [3]. During machining of titanium and its alloys by conventional processes, the above said characteristics lead to high temperature at cutting interfaces. The heat affected area effects the surface topography as it is an important surface property of its biological performance of titanium implants. Keeping in view the severity of machining of titanium and its alloys by conventional machining processes, the need of development of newer concept for machining of titanium with ease is emphasized. This necessitates the exploration of Advanced Manufacturing Processes (AMPs) for better machining [4].

Extensive basic and applied research during last decade has lead to the investigation of process performances of advanced machining processes to produce intricate details and maintaining to close tolerances in titanium and its alloys [5]. Among advanced machining processes, electrochemical machining with conventional honing that is hybrid Electro Chemical Honing (ECH) process is to be used increasingly in years to come, because of its many favorable features. The process is particularly useful for rapid removal of metal from the surface of formed or complex-shaped parts. In this process, the material is removed at atomic scale by electrolytic dissolution of ECM action and remaining by Honing. And therefore, the process can produce intricate details with good surface finish and moreover, it has no damaging effect on the mechanical properties of the metal. The favorable properties of titanium alloys make them suitable for a large number of applications but the higher production cost compared to many other metals limits in their use. High production cost of titanium alloy components is due to the high initial cost of material and difficulties associated with their fabrication and machining. The main issues related to poor machinability of titanium and its alloys have made to develop advanced machining processes. However, so far these investigations were carried out to provide precision finishing to the internal cylinders as well as gears. After that a number of researchers were carried out detailed study on ECH of gears and Cylinders. It is now one attempt to carry out the research on ECH of external cylindrical surfaces to discuss the highaccuracy, good surface finishing process based on ECH principle. The paper describes about the surface finishing of external cylindrical surfaces of $\mathrm{Ti}$ alloy $\mathrm{Ti} 6 \mathrm{Al} 4 \mathrm{~V}$. The electro chemical honing process is even used to obtain precise dimensions and surfaces in cylindrical shapes with a wide range of diameters.

\section{Electro chemical honing}

Electro Chemical Honing $(\mathrm{ECH})$ is one of the advanced manufacturing process which is having more scope in coming modern scenario [6]. ECH process has its own advantages to remove excess material obtaining uniform excellent surface finish. Electro chemical honing is a hybrid electrolytic micro finishing technology characterized by a distinct coupling of electro chemical machining (ECM) and conventional mechanical honing (MH) processes to provide controlled functional surface generation and fast material removal capabilities in a single operation. ECH can offer a unique range of benefits to the machined surface which cannot be obtained by either of the processes. The ability of ECH to apply these benefits productively, has lead to its widespread use in industries, especially in aerospace, automobiles, roller and gear manufacturing industries [7]. The ECH process is five to eight times faster than honing and four times faster than grinding. It can provide surface finish up to $0.05 \mu \mathrm{m}$. The ECH process offers an advantage of high metal removal rate and extreme accuracy of $0.001 \mathrm{~mm}$ in a wide variety of hard to cut materials [8].

The general principle of anodic metal removal was one of the discoveries of Michael Faraday (1791-1867) from which stemmed the development of electrochemical processes. The phenomenon of electrolysis was first studied scientifically more than 160 years ago and intentional electrolytic removal of metals has been practiced for many years in the electro pickling process which make use of electrolytic action to remove surface films from metal products. However, the application of ECM for machining of titanium and its alloys was initiated by Gosger in 1971 when he filed a patent on method of electrochemically machining titanium or titanium alloy work pieces [9]. After that Bannard picked up research on electrochemical machining of titanium alloys in bromide electrolytes and explained the efficiency of dissolution of some titanium alloys, stray attack properties of bromide electrolyte for titanium and polarization curves for titanium alloys in potassium bromide [10]. But, due to the principal problems associated with the inherent properties of titanium alloy, the electrochemical machining of these alloys has not kept pace with advances in the electrochemical machining of other materials. Within last few years, the researchers concentrate their focus on machining of titanium alloys using electrolytic dissolution based processes namely electrochemical micro-machining [11], ultrasound assisted electrochemical machining [12], micro-electrochemical polishing of titanium alloys [13]. In most recent work, Dhobe 
investigated the surface characteristics of ECMed titanium work samples for biomedical application [14]. But still, the electrochemical machining of titanium and its alloys is at infancy stage and need comprehensive study for its better understanding and commercialization with developed processes since they are not significantly explored. a review of the past research work reveals that there exists a lack of systematic investigation on ECM and ECH of titanium alloys.

ECH provides fine surface generation by honing and fast material removal by ECM in a single operation. Other advantages include the ability to correct out of roundness, cylindricity, circularity and axis straightness in relatively round cylindrical work pieces [15]. In the ECH finishing operation a very small amount of material is removed from the work piece by means of a honing process and remaining by an electrolyte. Many researchers [16, 17, 18] have carried out researchers in the field to explore various aspects of the ECH of bevel gears, spur gears and helical gears. Their study proves ECH as highly productive alternating finishing processes for the bevel gears what they actually achieved [19]. It has special feature of better understanding the ECH process and they found from experimental investigations to explore the influence on various process performance parameters like surface quality and process capabilities of interior system [20]. ECH has many advantages with regard to quality and productivity of finishing over the other conventional finishing methods, as the process is applied for machining to difficult to cut materials like hard materials as well as high density and high carbon content materials [21].

\section{Experimental details}

\subsection{Experimental setup}

Based on objectives of study, an experimental setup for surface finishing of external cylinders has been developed for the titanium alloys. As the process involves the electrolytic dissolution and mechanical scrubbing, the design, fabrication and material selection can achieve based on some relevant considerations such as technical data and other relevant information. For the present study, an experimental setup with modular tooling system has been indigenously developed as shown in Fig.1. Photographic view. With the assistance of modular changing tool system, the developed machine setup can provide the versatility of running ECH, ECM and Honing process in a single setup by incorporating different sizes of cylindrical components maintaining IEG. The experimental investigation has been conducted into first phase with pilot experiments. Pilot experiments have been carried out to study the effect of processing time, inter-electrode gap, electrolyte flow rate, electrolyte pressure and honing stone grit size on measures of process performance i.e. percentage improvement, in average surface roughness (PIRa) and material removal rate (MRR). The setup consists of power supply system, electrolyte supply system, tooling system, tool motion system and machining chamber with fixtures. A schematic diagram has been shown in Fig.2. The power supply system consists of 0-100 V and 100A DC supplying unit having provision for operating at both continuous and pulsating condition. This subsystem is employed to provide power supply to the anodic work piece and cathode tool to complete the electric circuit. The electrolyte supply system is consisting of reservoir, pump, flow meter, pressure gauges, heat exchanger, chamber drains, magnetic filters, settling tank, etc. The purpose of this sub-element is to supply the filtered electrolyte with controlled flow rate and pressure. The entire tooling system is enclosed in a machining chamber and it has provisions for supply of fresh electrolytes, for removal of used electrolyte, and for escape of gases generated during ECH process. The machining chamber is connected to the cast iron frame and is attached to the machine column of bench drilling machine using a swivel arrangement for ease in loading and unloading. After the proper alignment and positioning of the work piece and tool, work table can be locked in position. The abrasive action of the honing tool removes the material from the outer surface of work piece as the tool is designed for external cylindrical surface components. The tool rotates and reciprocates while the work piece is stationary fixed in machine chamber with foundation bolts fixed for unstability.

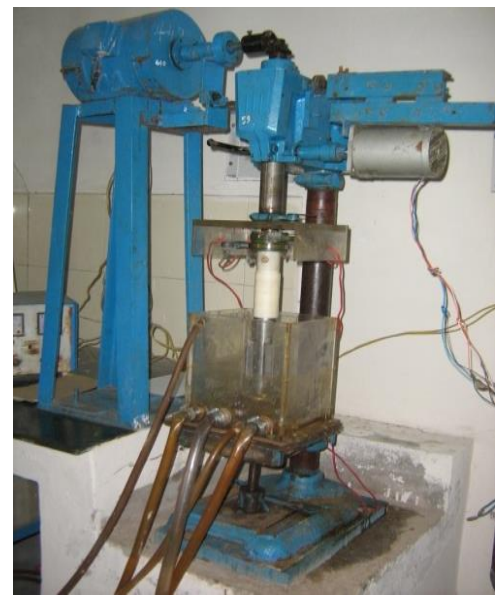

Fig. 1. Photographic view of ECH setup

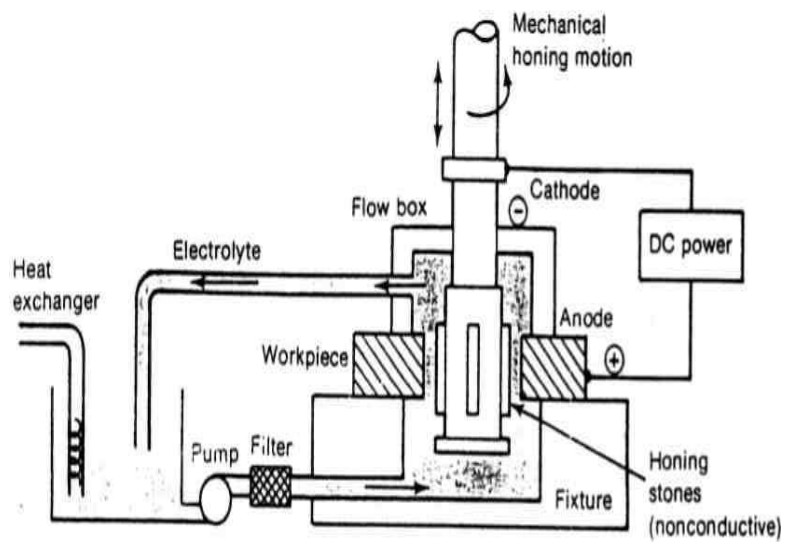

Fig. 2. Schematic view of ECH tool with Work piece Interaction. 
The rotary \& reciprocation movement of ECH tool is the single most important point in achieving the closer tolerances required and surface finish desired as shown in Fig. 3. Selection of the abrasive type and size (80 to 600 mesh sizes) depends on the type of work piece and the rate of surface finish required. The honing stones are mounted on a stain less steel tool holder which is simultaneously given a rotary motion as well as reciprocating (or oscillatory) motion to perform a complete cycle as shown in Fig.4. The rotary movement of tool can be controlled by stepper motor and while reciprocating motion can be controlled by micro controlled based programme. The machining chamber is made of Perspex to obtain a better visibility of the operation. Machine chamber consists of work piece fixture and ECH tool holder as shown in Fig.5 and Fig.6. respectively. The study also investigates the effects of process parameters on microstructure and surface roughness of the machined surface. Fig.7. shows the composition of Ti alloy examined by EDX technique and Table.1. Shows the level of composition of different elements. The inter-electrode gap (IEG) is maintained between work piece and the tool to avoid short circuiting and filled with the electrolyte. During this, non-conductive spring controlled honing tool is applied with controlled pressure on the work piece. Then the honing tool is given simultaneous rotary and reciprocating motions, as in conventional honing, to finish the work piece surface. The mechanism of material removal in ECH is based on the interaction between electrolytic actions with mechanical abrasion as explained earlier.

The surface roughness and bearing ratio values of the samples before and after the process are measured with a WYKO NT 1100 optical profilometer interfaced with Vision 32 software to find out the percentage improvement in surface roughness values. Material removal rate is measured by calculating amount of metal removed per unit processing time. The experimentations conducted to find out the optimal values of processing time, inter-electrode gap, electrolyte flow rate, honing stone grit size and electrolyte pressure and all the optimal values are identified by graphical analysis. Based on the results of pilot experiments, $08 \mathrm{~min}$ of processing time, $0.75 \mathrm{~mm}$ of inter- electrode gap, 1 MPa of electrolyte pressure, $30 \mathrm{lit} / \mathrm{min}$ of electrolyte flow rate, Grit Size of 600 mesh and $15 \%$ concentration of $(100 \%$ pure $\mathrm{NaCl}$ composition) are found optimum. IEG and electrolyte concentration have been found to have more significant effect on $\mathrm{ECH}$ process performance characteristics while of electrolyte pressure and electrolyte flow rate is found to have minimum significant effect. The input process parameters used in the study are independent of each other and as a result of this the interactive effects of input process parameters on process performance characteristics are found significant. The surface characteristics of electrochemical honed surface have been analyzed and it is found that ECH improves the surface quality by removing the small pits, micro-burrs, feed marks and irregularities. No significant changes in surface / sub-surface micro-structure and micro-hardness have been noticed. The surface roughness present in the surface after ECH is significantly reduced by the process as the roughness is in nano finish level.

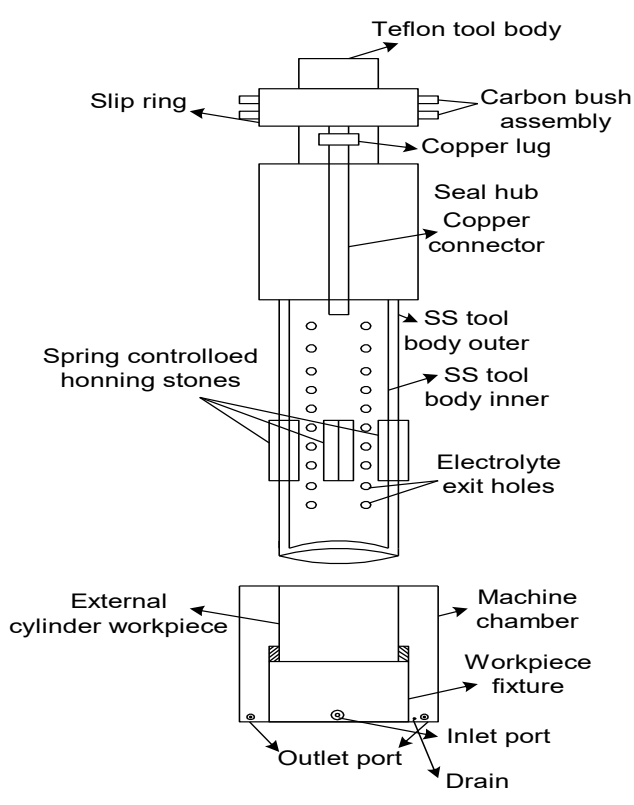

Fig. 3. Exploded view of ECH tool with work piece fixture 


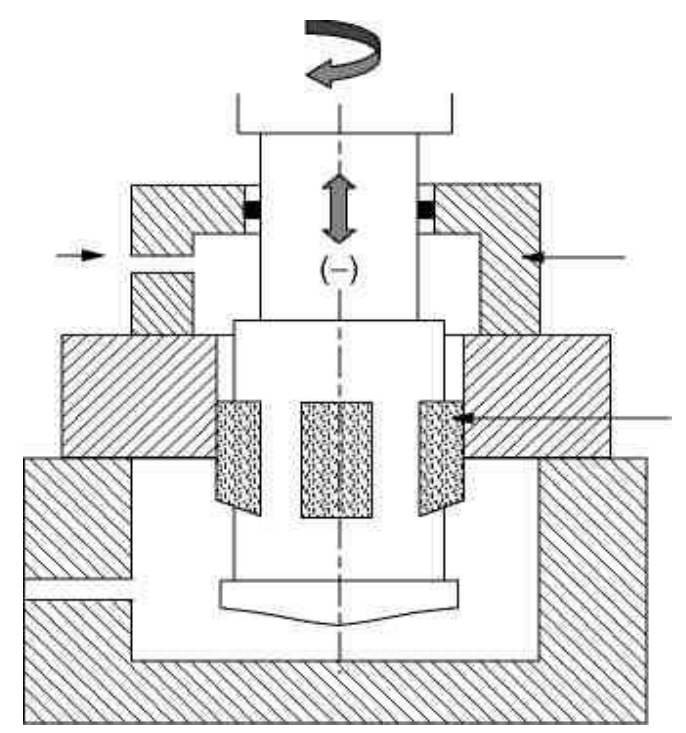

Fig. 4. Schematic view of ECH tool with rotation \& reciprocation motion

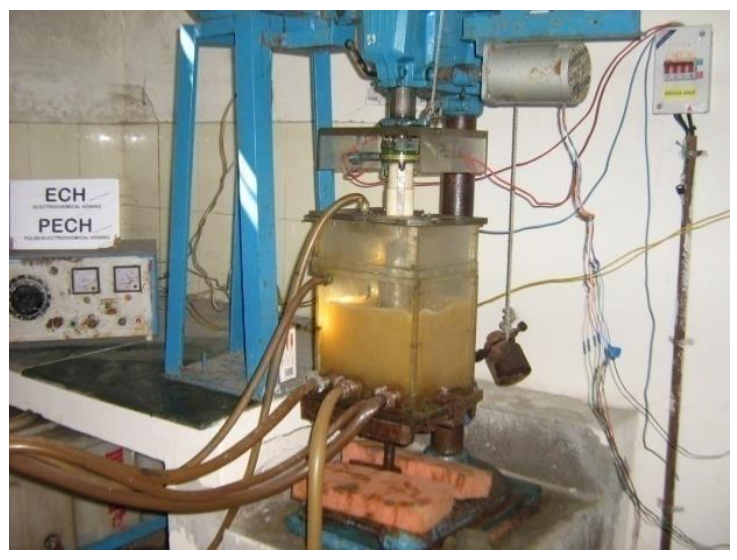

Fig. 5. Photographic view of ECH setup with electrolyte filled

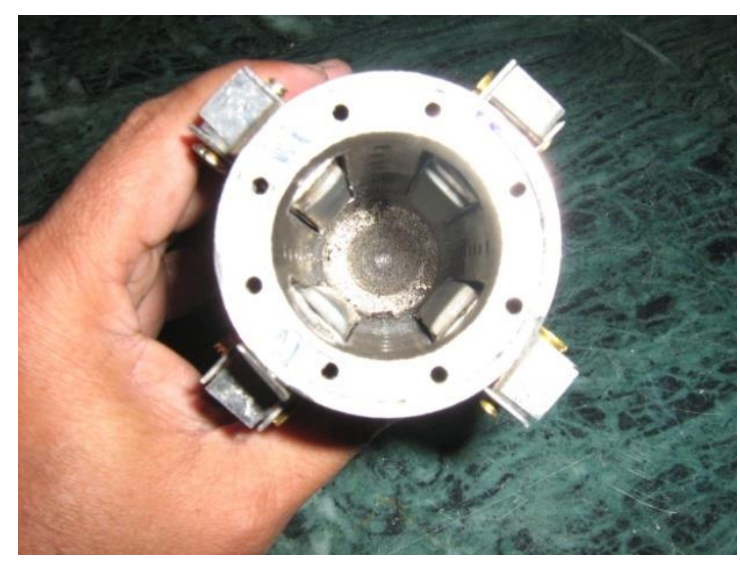

Fig. 6. Photographic view of ECH tool with honing stones

\subsection{Experimental Procedure}

To optimize the significant parameters and to evaluate the effect of process parameters on the process performance, the experiments on Ti alloys have been done by using one-parameter-at-a-time OFAT approach, which intern to explain the effects among various process parameters. Finishing time and other electrolyte-related parameters have been used as key process parameters in to the investigations to study their effect on the surface finishing performance of ECH. Initially the effect of finishing time has been examined through experiments by varying one factor at a time approach and also later electrolyte flow rate, electrolyte pressure, inter electrode gap, honing stone grit size and electrolyte concentration have been studied. The surface roughness values before and after ECH are measured. In this work, processing time was used as input process parameter and surface texture parameters were used as response parameter. The percentage improvements in surface roughness values were also calculated to visualize the improvement in the surface quality of Ti alloys. Table2. Presents the input and fixed process parameters selected for the experimentation. The parameters and their ranges were selected on the basis of literature review, pilot experiments and machining constraints.

Experimental investigations were carried out to study the surface roughness characteristics (i.e. Ra). Microhardness and surface integrity aspects were also examined. Pre-experiment and post-experiment measurements of process performance characteristics were examined using the suitable measuring instrument like Scanning Electron Microscopy (SEM) and Atomic Force Microscopy (AFM) to study the surface integrity and surface texture aspects of electrochemically honed external cylinders of Titanium alloys ( $\mathrm{Ti} 6 \mathrm{Al} 4 \mathrm{~V}$ ). The Composition of Ti6Al4V is obtained by EDX (Energy Dispersive X-ray) analysis. 


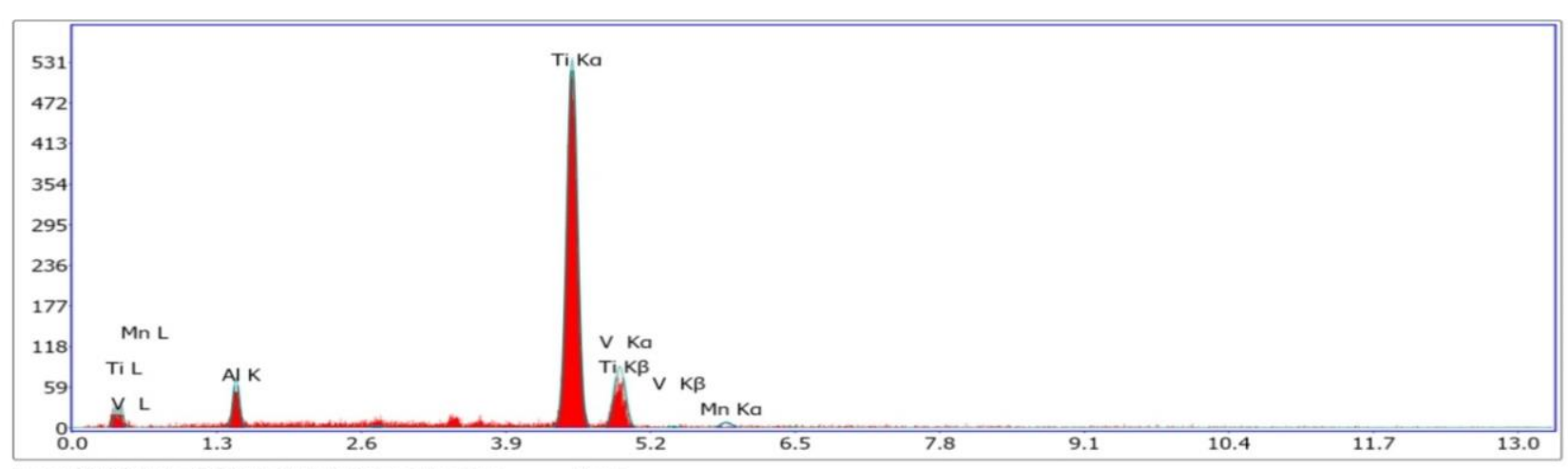

Lsec: 30.00 Cnts 0.000 keV Det: Octane Pro Det Reso

Fig. 7. Ti $6 \mathrm{Al} 4 \mathrm{~V}$ composition data by EDX analysis

\begin{tabular}{cccc}
\hline $\mathrm{Al}$ & $\mathrm{V}$ & $\mathrm{Ti}$ & $\mathrm{Sn}$ \\
\hline $5.0-6.0 \%$ & $3.0-4.0 \%$ & $85.0-90.0 \%$ & $0.50-0.90 \%$ \\
\hline
\end{tabular}

Table.1. Ti alloy Ti 6Al4V composition data by EDX

\begin{tabular}{ll}
\hline Parameter & Values \\
\hline Type of power supply & Continuous DC \\
Current & $20 \mathrm{~A}$ \\
Processing time & $08 \mathrm{~min}$ \\
Voltage & $30 \mathrm{~V}$ \\
Rotating speed & $60 \mathrm{rpm}$ \\
Electrolyte Temperature & $30 \mathrm{degrees}$ \\
Electrolyte Composition & $100 \%$ pure $\mathrm{NaCl}$ \\
Honing Stone & $\mathrm{SIC}$ \\
\hline
\end{tabular}

Table. 2. Values of input and fixed parameters for experimentation

\section{Results and discussion}

The surface roughness values obtained for Titanium alloys were noted after each experimentation. The values were noted for different processing time. Table 3 to 6 presents the surface roughness (Ra) value, of work piece before and after machining for each experimental run. The calculated percentage improvement in surface roughness values (PIRa) is also shown. The initial and final Ra values and the percentage improvement in surface roughness (PIRa) values both are presented in Table 3, 4, 5 and 6 for different IEG gaps, electrolyte flow rate, electrolyte pressure, electrolyte concentration and honing stone with diff grit size respectively. Percentage improvement in average surface roughness value (PIRa) is used as process response. A higher value in PIRa indicates better surface finish of work-surface as shown in Table 3, 4, $5 \& 6$ and this helps to study the material removal, finished surface characteristics and surface integrity aspects of ECH process.

\begin{tabular}{cccccccccc}
\hline \multirow{2}{*}{$\begin{array}{l}\text { IEG } \\
\text { in um }\end{array}$} & \multicolumn{2}{c}{ Top portion of cylindrical w/p } & \multicolumn{3}{c}{ Middle portion of cylindrical w/p } & \multicolumn{3}{c}{ Bottom portion of cylindrical w/p } \\
\cline { 2 - 10 } & Before & After & PIR $_{\mathrm{a}}$ & Before & After & PIR $_{\mathrm{a}}$ & Before & After PIR $_{\mathrm{a}}$ \\
\hline 1.00 & 1.58 & 0.630 & 60.12 & 1.46 & 0.660 & 54.72 & 1.59 & 0.615 & 61.32 \\
0.75 & 1.65 & 0.640 & 63.03 & 1.54 & 0.412 & 73.25 & 1.46 & 0.510 & 64.83 \\
0.50 & 1.42 & 0.301 & 78.80 & 1.50 & 0.314 & 79.01 & 1.41 & 0.304 & 75.44 \\
0.25 & 1.58 & 0.410 & 74.05 & 1.56 & 0.410 & 73.32 & 1.58 & 0.418 & 74.25 \\
\hline
\end{tabular}

Table. 3. Average surface roughness and percentage of improvement in average surface roughness values at different Inter Electrode Gap 


\begin{tabular}{|c|c|c|c|c|c|c|c|c|c|}
\hline \multirow{2}{*}{$\begin{array}{c}\text { Electrolyte Flow rate } \\
\text { In lit } / \mathrm{min}\end{array}$} & \multicolumn{3}{|c|}{ Top portion of cylindrical $w / p$} & \multicolumn{3}{|c|}{ Middle portion of cylindrical $w / p$} & \multicolumn{3}{|c|}{ Bottom portion of cylindrical $w / p$} \\
\hline & Before & After & $\mathrm{PIR}_{\mathrm{a}}$ & Before & After & $\mathrm{PIR}_{\mathrm{a}}$ & Before & After & $\mathrm{PIR}_{\mathrm{a}}$ \\
\hline 20 & 1.58 & 0.410 & 74.05 & 1.54 & 0.412 & 73.25 & 1.41 & 0.320 & 77.30 \\
\hline 25 & 1.46 & 0.314 & 78.49 & 1.48 & 0.310 & 79.05 & 1.52 & 0.315 & 79.28 \\
\hline 30 & 1.52 & 0.209 & 86.91 & 1.51 & 0.215 & 85.76 & 1.49 & 0.210 & 85.95 \\
\hline 35 & 1.41 & 0.320 & 77.30 & 1.50 & 0.315 & 79.00 & 1.45 & 0.312 & 78.48 \\
\hline
\end{tabular}

Table. 4. Average surface roughness and percentage of improvement in average surface roughness values at different Electrolyte Flow rate

\begin{tabular}{cccccccccc}
\hline \multirow{2}{*}{$\begin{array}{c}\text { Electrolyte Pressure in } \\
\text { MPa }\end{array}$} & \multicolumn{3}{c}{ Top portion of cylindrical } & \multicolumn{3}{c}{ Middle portion of cylindrical w/p } & \multicolumn{3}{c}{ Bottom portion of cylindrical w/p } \\
\cline { 2 - 10 } & Before & After & PIR $_{\mathrm{a}}$ & Before & After & PIR $_{\mathrm{a}}$ & Before & After & PIR $_{\mathrm{a}}$ \\
\hline 0.5 & 1.61 & 0.620 & 61.49 & 1.69 & 0.610 & 63.90 & 1.58 & 0.630 & 60.12 \\
1.0 & 1.58 & 0.418 & 74.25 & 1.41 & 0.304 & 75.44 & 1.58 & 0.410 & 74.05 \\
1.5 & 1.46 & 0.510 & 64.83 & 1.52 & 0.520 & 65.79 & 1.65 & 0.640 & 63.03 \\
2.0 & 1.59 & 0.615 & 61.32 & 1.45 & 0.650 & 55.48 & 1.46 & 0.660 & 54.72 \\
\hline
\end{tabular}

Table. 5. Average surface roughness and percentage of improvement in average surface roughness values at different Electrolyte Pressure

\begin{tabular}{cccccccccc}
\hline \multirow{2}{*}{ SIC Grit Size } & \multicolumn{2}{c}{ Top portion of cylindrical w/p } & \multicolumn{3}{c}{ Middle portion of cylindrical w/p } & \multicolumn{3}{c}{ Bottom portion of cylindrical w/p } \\
\cline { 2 - 10 } & Before & After & PIR $_{\mathrm{a}}$ & Before & After & PIR $_{\mathrm{a}}$ & Before & After & PIR $_{\mathrm{a}}$ \\
\hline 120 & 1.52 & 0.520 & 65.79 & 1.52 & 0.520 & 65.79 & 1.65 & 0.640 & 63.03 \\
360 & 1.54 & 0.412 & 73.25 & 1.41 & 0.320 & 77.30 & 1.58 & 0.410 & 74.05 \\
600 & 1.50 & 0.315 & 79.00 & 1.46 & 0.314 & 78.49 & 1.52 & 0.315 & 79.28 \\
1200 & 1.56 & 0.410 & 73.32 & 1.58 & 0.418 & 74.25 & 1.41 & 0.304 & 75.44 \\
\end{tabular}

Table. 6. Average surface roughness and percentage of improvement in average surface roughness values at different Grit Sizes of honing stone

Micro-structure study and micro-structure characterization have been carried out to investigate the impact of the process on surface integrity aspects of the machined surface. SEM images of the cut surfaces have revealed that the fine surface finish was obtained when machining was done at a combination of lower levels of input process parameters. When machining was done at combination of higher levels of input process parameters, some burrs arise on the machined surface which can be examined by microscope as well as SEM and FESEM.

From the experimental results, it can be observed that a very good improvement in average surface roughness $\mathrm{Ra}$ is achieved. If IEG parameter is concerned, total percentage improvement in surface roughness Ra is about $78.80 \%$ at top portion of the cylindrical work piece, $79.01 \%$ at middle portion of the cylindrical work piece and $75.44 \%$ at bottom portion of the cylindrical work piece respectively obtained at 08 minutes of finishing time as as shown in Table 3.

If an electrolyte flow rate parameter is concerned, Table 4 results reveals that better surface finish at maximum $301 /$ min of electrolyte flow rate and shows a very good percentage improvement in surface finish about $86.91 \%$ at top portion, $85.76 \%$ at middle portion and $85.95 \%$ at bottom portion of the cylindrical work piece respectively. Fig. 12. Shows 2D histogram data of ECHed Ti alloy Ti6Al4V by AFM technique.

From the results of $100 \%$ pure $\mathrm{NaCl}$ electrolyte composition parameter is concerned, the Table 5 describes that, the $100 \% \mathrm{NaCl}$ solution with $1 \mathrm{MPa}$ electrolyte pressure gives better surface finish and shows a very good percentage improvement in surface finish about $74.25 \%$ at top portion, $75.44 \%$ at middle portion and $74.05 \%$ at bottom portion of the cylindrical work piece respectively at $15 \%$ of concentration level of $\mathrm{NaCl}$ solution.

Fig.13. shows AFM analysis of 3D surface finish of ECHed surfaces. In both the cases, there is considerable decrease in surface roughness with increase in processing time. If honing stone parameter is concerned, from the Table 6 it is evident that, the 600 Grit size of $\mathrm{SiC}$ gives better surface finish and shows a very good percentage improvement in 
surface finish about $79.00 \%$ at top portion, $78.49 \%$ at middle portion and $79.28 \%$ at bottom portion of the cylindrical work piece respectively at $15 \%$ of concentration level of $\mathrm{NaCl}$ solution.

Fig.14. shows SEM photographs of electrochemically honed (ECHed) Ti alloy work piece surface (a) before $\mathrm{ECH}$ and (b) after $\mathrm{ECH}$. As the $\mathrm{ECH}$ process is feasible for better material removal and shiny finishing look. It is evident from the plots that the surface roughness present in the surface after $\mathrm{ECH}$ is significantly reduced by this process and useful for further study to have the glimpses of ECH forecast.

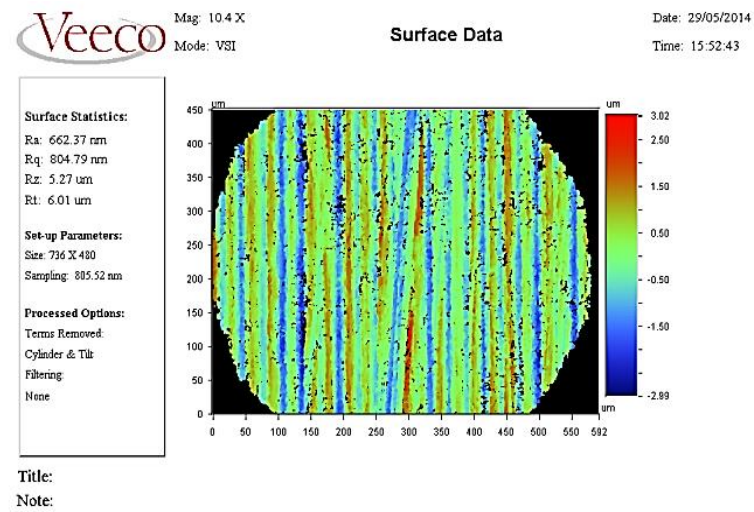

Fig. 8. Average surface roughness data

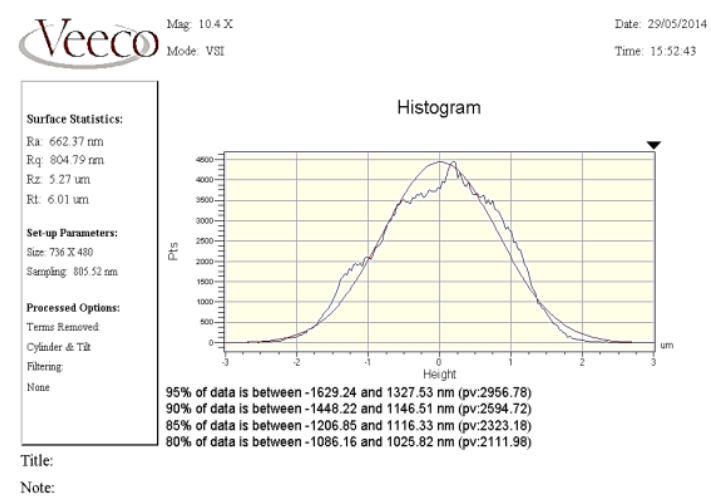

Fig.10. Average surface roughness histogram data

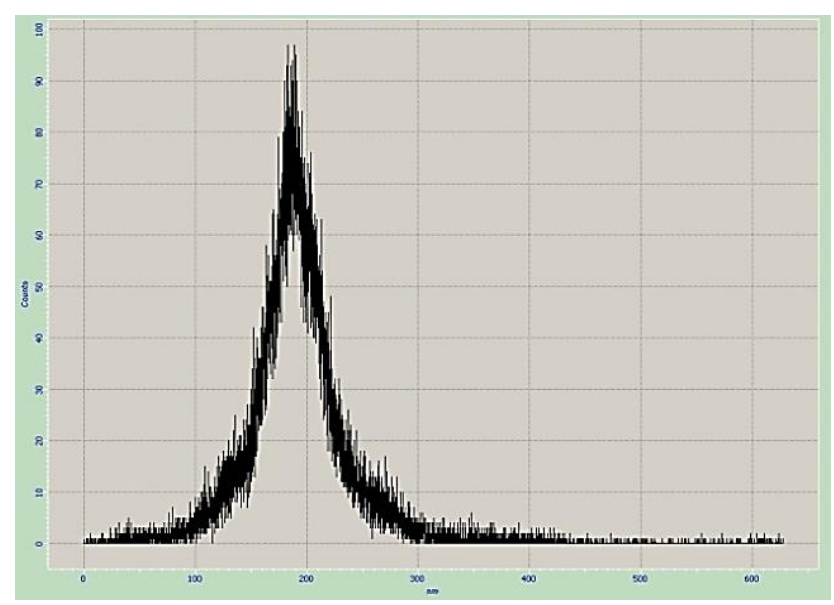

Fig. 12. 2D histogram by AFM analysis

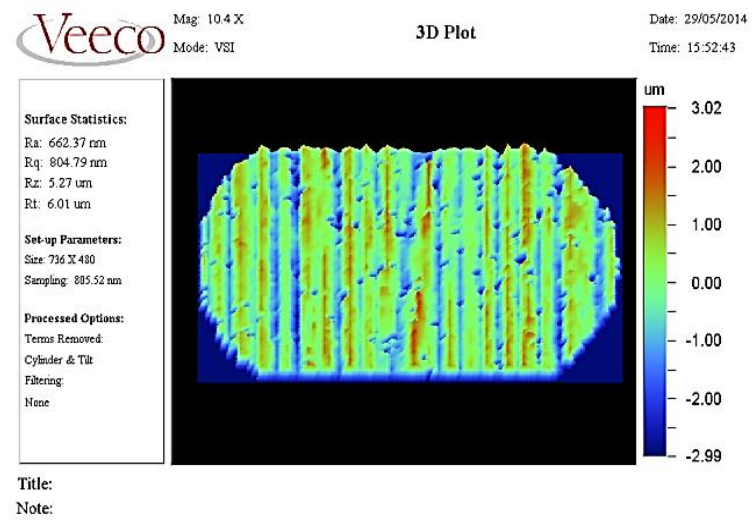

Fig. 9. Average surface roughness 3D plot data.

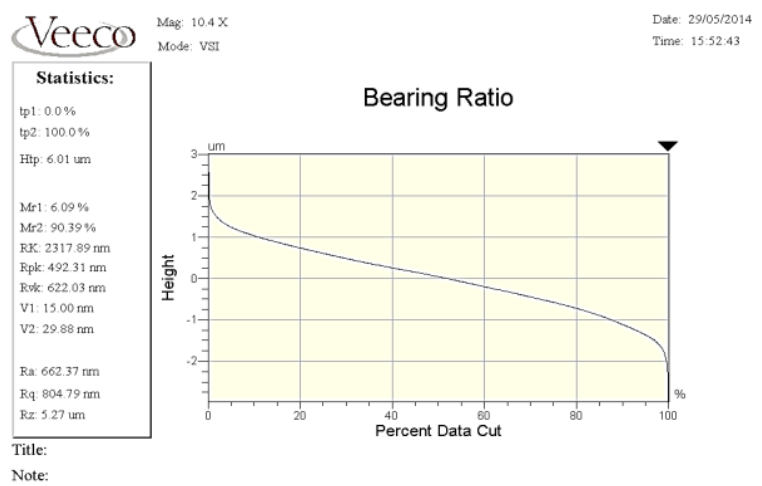

Fig. 11. Average surface roughness bearing ratio data

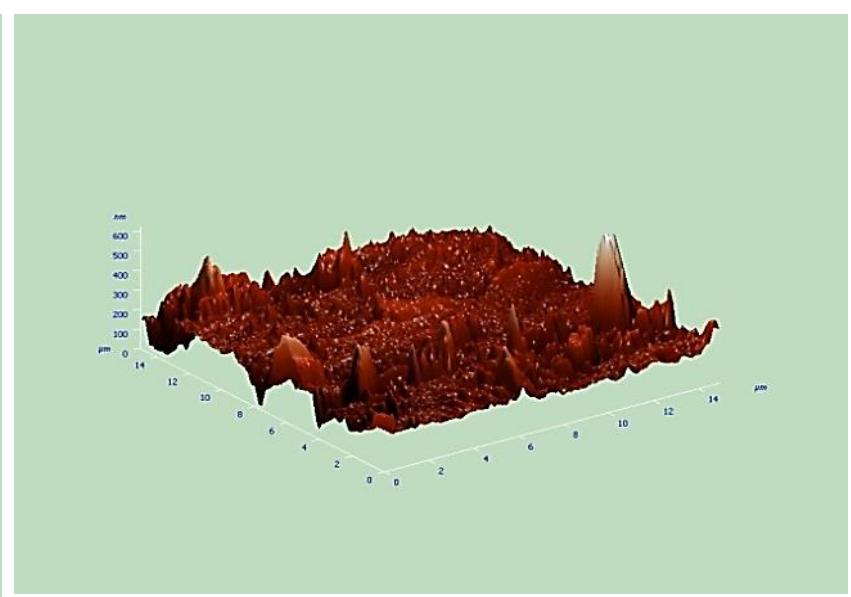

Fig. 13. 3D surface finish by AFM analysis 

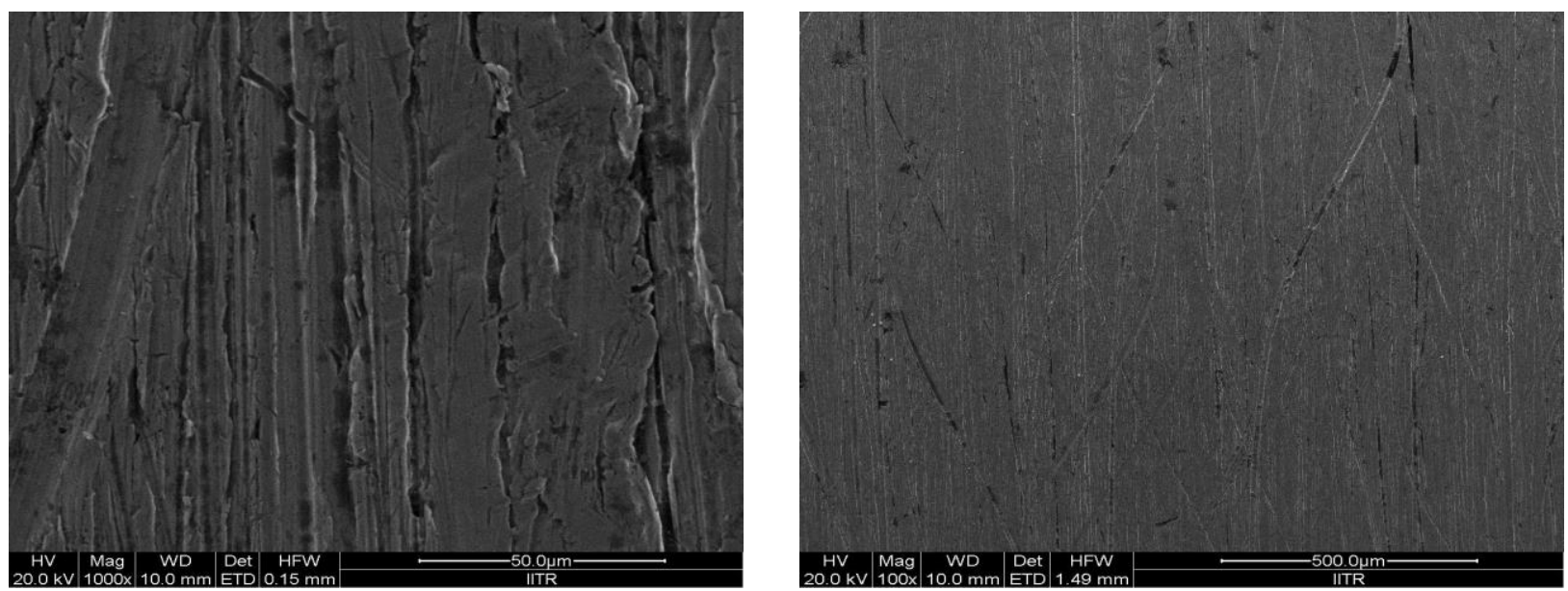

Fig. 14. SEM photographs of electro chemically honed (ECHed) Ti alloy TI6Al4V surface (a) before ECH and (b) after $\mathrm{ECH}$

\section{Conclusion and future scope}

Conclusion can be made based upon the results of experiments as, 08 minutes as finishing time, $0.75 \mathrm{~mm}$ inter electrode gap, $30 \mathrm{lit} / \mathrm{min}$, electrolyte flow rate, $1 \mathrm{MPa}$ of electrolyte pressure, 600 mesh of SiC grit size of honing stone and $15 \%$ of $\mathrm{NaCl}$ pure electrolyte solution are found optimum for precision super finishing of titanium alloys. The result shows that, all the five parameters are highly important to achieve the better surface finish.

In the experiments, an attempt was made to study the effects of input process parameters on processing time, IEG, electrolyte flow rate, electrolyte pressure, electrolyte concentration and honing grit size and also found that they play a significant role in the minimization of surface roughness. This paper establishes the feasibility of using ECH for high precision finishing of Ti alloys to improve the micro-topographical characteristics .It is evident, that the processing time has immense influence on material removal mechanism of the process. The study illustrates that initially the processing rate is high, but it slows down as the processing time increases. But even with increased processing time, its productivity and mechanical properties are good enough. It is also found, that the process is highly capable of reducing the irregularities on cylindrical surfaces of various diameters.

Like most of the hybrid machining processes, ECH is also in the development phase and therefore, a sustained global research is still required to perform it into other tough materials as well as other process parameters. Further research could consider the study of effect of different parameters like current, voltage, rotating speed of the tool, reciprocating motion of the tool and other different electrolyte related parameters on surface quality for its successful industrial applications, commercialization and matured technology. A ray of hope is there for better future manufacturing processes in near future. Further study is in progress to look in to other response parameters like cylindricity, circularity, diameter decrease rate, out of roundness and axis deviation etc for cylindrical components and circular shafts. The complex interactions of the electrical, chemical and mechanical characteristics are not completely recognised so far. Extensive research efforts and continuing advancements in enabling technologies are required for improvement in hybrid machining and further most in ECH.

\section{References}

[1] M.E. Merchant, The manufacturing system concept in production engineering research, CIRP Annals, 10 (1961) 7783.

[2] X. Lu, Y. Leng, Electrochemical micromachining of titanium surfaces for biomedical applications, J. of Materials Processing Technology, 169 (2005) 173-178.

[3] S. Sun, M. Brandt, M.S. Daragusch, Characteristics of cutting forces and chip formation in machining of titanium alloys. Int. J. of Machine Tools \& Manufacture, 49 (2009) 561-568.

[4] G.F. Benedict, Non traditional manufacturing processes, Marcel Dekker, New York, 1987.

[5] P.C. Pandey, H.S. Shan, Modern machining proncesses, Tata McGraw-Hill Publishing Company, New Delhi, 1980.

[6] El-Hofi, Fundamentals of machining processes, McGraw-Hill Book Company, New York, 2005.

[7] J.P. Misra, H. Singh, P.K. Jain, N.K. Jain, Parametric optimization of pulse-electrochemical honing by response surface methodology, Proceedings of 4th Int. Conf. Advances in Mechanical Engineering, eds. R. V. Rao, Surat, India, (2010) 331-335.

[8] A.K. Dubey, Experimental investigations on electro $\neg$ chemical honing, Proceedings of IMechE, Part B: J. Engineering Manufacture, 222 (2008) 413-426.

[9] A.E. De Burr, D.A. Oliver, Electro chemical machining, Macdonald \& Company Limited, 1968. 
[10] J. Bannard, On the electrochemical machining of some titanium alloys in bromide electrolytes, J. of Applied Electrochemistry, 6 (1976)

477-483.

[11] L.M. Jiang, W. Li, A. Attia, Z.Y. Cheng, J. Tang, Z.Q. Tian, Z.W. Tian, A potential method for electrochemical micromachining of titanium alloy Ti6Al4V, J. of Applied Electrochemistry, 38 (2008) 785-791.

[12] H. Jianhua,Wang Wei, Ultrasound aided through-mask electrochemical micromachining of micro-hole array in titanium, China Mechanical Engineering, 19(22), 2008, 2670-2071.

[13] Tae-Hee Shin,Seeung-Yub Baek, Eun-Sang Lee, Micro electrochemical polishing of TiNi alloy for medical stent, Advanced Materials Research, 79-82 (2009)155-162.

[14] S.D. Dhobe, B. Doloi, B. Bhattacharyya, Surface characteristics of ECMed titanium work samples for biomedical applications, Int. J. of Advanced Manufacturing Technology, 55(1-4) (2011)177-188.

[15] L.R. Naik, Investigation on precision finishing of gears by electrochemical honing, M.Tech Dissertation, Mecha $\neg$ nical and Industrial Engineering Department, I.I.T. Roorkee, 2008.

[16] J.P. Misra, P.K. Jain, D.K. Dwivedi, Electrochemical honing-A novel technique for gear finishing, DAAAM International Scientific Book Chapter 29 (2011) 365-382.

[17] J.P. Misra ,P.K. Jain, R. Sevak, ECH of spur gears-A step towards commercialization, DAAAM International Scientific Book, Chapter

17 (2012) 197-212.

[18] J.H. Shaikh, N.K. Jain, High quality finishing of bevel gears by ECH- DAAAM International Scientific Book, Chapter 41 (2013) 697-710.

[19] J.P. Misra, P.K. Jain, D.K. Dwivedi, N.K. Mehta, Study of time dependent behaviour of Electro Chemical Honing $(\mathrm{ECH})$ of bevel gears,

24th DAAAM International symposium on intelligent manufacturing and automation 2013, J. of Procedia Engineering, 64 (2013) 1259-1266.

[20] P.S. Rao, P.K. Jain, D.K. Dwivedi, Electro Chemical Honing (ECH) of external cylindrical surfaces of titanium alloys, 25th DAAAM International symposium on intelligent manufacturing and automation 2015, J. of Procedia Engineering, 100 (2015) 936-945.

[21] P.Sudhakar Rao, P.K. Jain, D.K. Dwivedi, Precision finishing of external cylindrical surfaces of EN8 steel by electro chemical honing $(\mathrm{ECH})$ process using OFAT technique, 4th International Conference on Materials Processing and Characterization 2015, J. of Materials Today Proceedings, 2 (2015) 3220-3229. 